\title{
Response to: Comment to "No-Drain Single Incision Liposuction Pull-Through Technique for Gynecomastia"
}

\author{
Ashraf A. Khalil ${ }^{1}$ Amr Ibrahim ${ }^{1}$ Ahmed M. Afifi,
}

Received: 3 March 2017/Accepted: 12 March 2017/Published online: 3 April 2017

(C) Springer Science+Business Media New York and International Society of Aesthetic Plastic Surgery 2017

No Level Assigned This journal requires that authors assign a level of evidence to each article. For a full description of these Evidence-Based Medicine ratings, please refer to the Table of Contents or the online Instructions to Authors www.springer.com/00266.

We thank the authors for their commentary on our article. Their commentary is mostly a summary of their previous publication, in which they reported their experience with gynecomastia surgery through a periareolar incision with a few added modifications. We agree that an open excision through a periareolar incision is direct, reproducible, and easy to replicate, which is likely why it is a very common approach. For all the reasons we have described in our article, we find the liposuction pullthrough technique to be, in our hands, a superior approach as it is simple, safe, fast, and easy to learn. We prefer to avoid the surgical creation and undermining of large flaps, with the possible consequences of hematomas, irregularities, additional operating time, and need to place a drain. Doing the liposuction first makes the excision much easier and faster. Another benefit to our approach that is not mentioned in our article is that surgeons can always start the surgery aiming to use the liposuction pull-through technique; if they are not satisfied they can then easily convert to the open approach. We all would prefer the approach that has fewer complications, less scars, and shorter operative time, and it is up to the individual surgeon to decide which approach can deliver that in their hands and for every particular patient.

\section{Compliance with Ethical Standards}

Conflict of interest The authors declare that they have no conflicts of interest to disclose.
Ahmed M. Afifi

ahafifi@yahoo.com

1 Cairo University, Cairo, Egypt

2 Plastic and Reconstructive Surgery, University of WisconsinMadison, G5/356 CSC, 600 Highland Avenue, Madison, WI 53792, USA 